\title{
Do Individual Investors Trade Stocks as Gambling? Evidence from Repeated Natural Experiments*
}

\author{
Xiaohui Gao ${ }^{\mathrm{a} \dagger}$ Tse-Chun Lin ${ }^{\mathrm{b}}$ \\ ${ }^{a}$ School of Economics and Finance, University of Hong Kong, Hong Kong \\ ${ }^{b}$ School of Economics and Finance, University of Hong Kong, Hong Kong
}

\begin{abstract}
Multiple natural experiments of large jackpot lotteries in Taiwan are used to document that some individual investors trade stocks as a form of gambling. Those investors substitute lottery gambling for stock trading. This substitution effect between lottery and stock is substantiated by the following five key findings. First, when the jackpot exceeds 500 million Taiwan dollars (about 15 million U.S. dollars), the number of shares traded by individual investors decreases by about 7\% among stocks with high individual trading fraction, low market capitalization, high past returns, and high past turnover. Second, the reduction in individual trading is about $7 \%$ among stocks with lottery features, i.e. high return volatility and skewness. Third, the magnitude of the decline increases monotonically with the jackpot. Fourth, firm-level trading activity reacts negatively to large jackpots, and is statistically significant for a sizable number of firms. Finally, the aggregate trading activity by individual investors declines by about $5 \%$ on large jackpot days.
\end{abstract}

JEL Classification: G10, G12, G13, C51.

Keywords: Natural experiments; lottery; stock trading; substitution effect; investor attention; behavioral trading needs.

\footnotetext{
${ }^{*}$ We thank Gurdip Bakshi, Mark Seasholes, Scott Weisbenner, and participants at the Asia Finance Association International Conference 2010, the International Symposium on Financial Engineering and Risk Management 2010, and the University of Hong Kong for helpful comments and suggestions. The authors gratefully acknowledge the research support from the Faculty of Business and Economics at the University of Hong Kong and the Research Grants Council of the Hong Kong SAR government. Any remaining errors are ours.

†Tel.: +852-2859-1031; fax: +852-2548-1152. E-mail address: xiaohui@hku.hk.

†Tel.: +852-2857-8503; fax: +852-2548-1152. E-mail address: tsechunlin@hku.hk.
} 


\section{Introduction}

Recent research proposes that some individual investors view trading in the stock market as an opportunity to gamble. Barber, Lee, Liu, and Odean (2009) suggest that part of the excessive trading by Taiwan individual investors is driven by their gambling desire. Kumar (2009) uses socioeconomic characteristics of investors as their propensity to gamble and shows that such propensity is correlated with their investment decisions. Dorn and Sengmueller (2009) show that investors who report enjoying investing or gambling rebalance their portfolio at twice the rate of their peers in a survey study.

Our contribution is to take advantage of multiple natural experiments of large jackpot lotteries in Taiwan to directly test the hypothesis that some individuals gamble in the stock market. We find that these investors substitute lottery gambling for stock trading when the lottery jackpot is large. This substitution effect is substantiated by addressing the following five questions: Does the presence of large lotteries reduce shares traded for stocks which manifest greater behavioral biases on the part of individual investors? Does trading activity of stocks with lottery features decline on large lottery jackpot days? How strong is the substitution effect between lottery and shares traded, as the jackpot increases? Do lotteries impact firm-level trading activities? And finally, is the effect also discernible at the aggregate market level?

Several features motivate us to study the lottery and stock market behavior in Taiwan. First, a large jackpot lottery can be regarded as a natural experiment because it is an outcome of probability and is unlikely to be driven by factors that affect the stock market. Meanwhile, the reverse causality that lower trading in the stock market could meaningfully raise the jackpot is improbable. Second, the Public Welfare lottery has been popular since its inception in 2002, while other forms of gambling are prohibited in Taiwan. Third, on average, about $70 \%$ of the trading value in the Taiwan stock market (TSE) originates from individual investors, as opposed to other major stock markets where institutional investors typically dominate. With high individual investor participation in the stock market and no other legal gambling venues, Taiwan offers a tractable setting to empirically investigate the relation between lottery jackpot and individual trading activity in the stock market.

Lottery can be a substitute for stock among individual investors who have the propensity to 
gamble in the stock market for two reasons. First, buying a lottery ticket is a form of gambling (e.g., Brenner and Brenner (1990), Statman (2002), and Kumar (2009)). Second, lottery's payoff is positively skewed, a feature preferred by investors under the cumulative prospect theory (e.g., Tversky and Kahneman (1992) and Barberis and Huang (2008)). Importantly, we conjecture that only when the jackpot is large, the lottery becomes sufficiently salient and attracts enough investors that the substitution effect between lottery and stock can be discernible.

Based on hand-collected lottery data from January 2002 to December 2009, we present evidence that the effect of large jackpot on individual trading activity is pronounced among stocks that are favored by individual investors. ${ }^{1}$ Stocks associated with high individual trading fraction, low market capitalization, high past returns, and high past turnover experience a reduction in shares traded by about $7 \%$ on days with a jackpot in excess of 500 million TWD (about 15 million U.S. dollars), whereas the effect is statistically insignificant for stocks sharing the opposite property.

An equally strong substitution effect is observed for stocks with lottery features. Particularly, the shares traded of stocks with high return volatility and skewness are seen dropping by about $7 \%$ on large lottery days. In light of the behavioral biases of individual investors, trading in more speculative stocks is accordingly more severely affected when the jackpot is large, which appears consistent with the arguments of Barberis and Huang (2008) and Kumar (2009).

Whereas buying lottery with a large jackpot can be a substitute for stock trading by individual investors, a larger prize amplifies the thrill of lottery participation. The crucial insight garnered from our results is that the size of the jackpot matters, and the magnitude of the substitution effect increases monotonically in the lottery jackpot.

With respect to firm-level effects, our results offer complementary supportive evidence: the number of shares traded by individual investors drops, on average, by $7.4 \%$ if there is a large jackpot lottery drawing on the same day. The negative impact on trading activity is statistically relevant for more than $22 \%$ of the sample firms.

We also substantiate a substitution effect between lottery buying and trading by individual in-

\footnotetext{
${ }^{1}$ See Gompers and Metrick (2001), Hirshleifer (2001), Foucault, Sraer, and Thesmar (2010), Barber and Odean (2008), and Falkenstein (1996).
} 
vestors in the aggregate. For instance, when the lottery jackpot size exceeds 500 million Taiwan dollars, the reduction in the total number of shares traded by individual investors, the total value traded by individual investors, and the individual turnover rate are 5.1\%, 5.2\%, and 6\%, respectively. The negative impact of lottery on individual trading is both economically and statistically significant.

Our paper is most related to Barber, Lee, Liu, and Odean (2009). They use a complete trading history of all investors in Taiwan during 1995 to 1999 and document that individual investor trading results in systematic and economically large losses. Analyzing the market turnover rate before and after the introduction of the Public Welfare lottery in 2002, they propose that part of the excessive trading by individual investors is driven by their gambling desire. ${ }^{2}$

However, our paper differs from theirs in two key ways, and yet complements their study. First, instead of studying a one-time event, we use our lottery data to explore a series of drawings with large jackpots over eight years. The repeated event setting enables us to more directly analyze the substitution between two gambling venues, i.e. lottery and stock. Second, the time-series setting allows a comprehensive documentation of the substitution effect both among groups of stocks with different characteristics, and also at the individual firm level.

The rest of the paper proceeds as follows. Section 2 describes the lottery and stock market data underlying our natural experiment, while Section 3 presents our empirical results. Conclusions and summary of our findings are provided in Section 4.

\section{Data description of the natural experiments}

Before proceeding to details of our data, we emphasize that we study repeated natural experiments in which the presence of a large lottery serves as an instrument for days when individual investors' need for gambling is manifested by buying lottery. The idea is that the thrill of the lottery jackpot,

\footnotetext{
${ }^{2}$ Previous studies reveal other behavioral reasons to trade. Among others, Grinblatt and Keloharju (2009) show that overconfident investors, and those investors more prone to sensation seeking, trade more frequently. Dorn and Sengmueller (2009) show that investors who report enjoying investing rebalance their portfolio at twice the rate of their peers in a survey study. They argue that the entertainment value of trading plays a role to explain the "excessive trading puzzle."
} 
perhaps intensified by the media coverage around the event, substitutes some individual investors' need for gambling in the stock market. This substitution effect can be more explicitly identified within our natural experiment setting.

\subsection{Lottery and large jackpots}

Since our interest lies primarily in the link between large jackpots and stock trading by individual investors, our empirical inquiry includes the three major lotteries in Taiwan, namely, Lotto, Big Lotto, and Super Lotto. Lotto was introduced on January 22, 2002. Big Lotto was introduced in 2004, and in 2007, Lotto was replaced by Super Lotto. We describe the institutional details of the three lotteries in the Appendix I.

The media usually reports the cumulated prize of a lottery drawing as its jackpot, so we use the two terms interchangeably. Table 1 shows descriptive statistics of the lottery jackpot size between 2002 to 2009. In total, we have 1,495 lottery drawings (see column 2), ranging from 99 drawings in 2002 to 248 in 2006 . The data is hand collected from the website of the bank which holds the exclusive rights to administer the lottery.

Inspection of Table 1 also shows that the calender year mean of the jackpot ranges from 147 million TWD to 470 million TWD, over 2002 to 2009. The maximum winnable jackpot prize was 2.93 billion TWD.

For the vast majority of our analysis, a large jackpot is taken to be a cumulated lottery prize above 500 million TWD, which roughly represents the 90th percentile value of the sample. Hence, we also report, in Table 1, the number of lottery drawings with a jackpot larger than 500 million TWD. There is some variation in the number of large jackpot drawings over our eight year sample, ranging between 11 and 37 drawings. In total, there are 163 large jackpot lotteries above 500 million TWD.

Large jackpots, such as those above 500 million, only occur after a series of no winners, and they are governed by pure probability outcomes and are unlikely to be drive by factors that also move the stock market. Therefore, we regard these 163 large lottery jackpots as a series of natural 
experiments, and subsequently use them as instruments of gambling.

\subsection{Stock market and trading activity}

Data on our natural experiment also includes matching daily stock market data from TSE. Excluding firms with less than 100 trading day observations leaves 734 individual stocks in our sample, and includes individual investor trading activity in each stock. Table 2 reports the median of daily trading activity variables across all years, and in each calendar year from 2002 to 2009.

The first data trait worth emphasizing is that stock market trading is dominated by individual investors: the ratio of shares traded by individual investors over total shares traded ranges between $52 \%$ to $76 \%$ (compare columns 2 and 3). Such a high individual investor participation rate indicates that behavioral biases, if any, could exert an identifiable impact on the stock market.

In our analysis, the daily market turnover is the number of shares traded divided by the sum total of the number of shares outstanding on the TSE, the same as the equal weighted aggregate market turnover in Baker and Wurgler (2007). The median daily market turnover is around 0.61\%, somewhat larger than the value-weighted aggregate turnover of $0.45 \%$ for S\&P 500 index stocks (see Chordia, Roll, and Subrahmanyam (2010, Table 1)). Individual turnover is analogously the number of shares traded by individual investors divided by the total shares outstanding in the market. The median daily individual turnover is around $0.39 \%$.

The average stock price is $20 \mathrm{TWD}$, and the minimum transaction size is 1,000 shares, so the average minimum transaction value is 20,000 TWD, which is equivalent to 400 (200) Lotto and Big Lotto (Super Lotto) tickets. In addition, lottery sales over the value of shares traded, as seen from the last column of Table 2, decreases gradually from $0.97 \%$ to $0.10 \%$ from the lottery debut to the last three years in our sample. Therefore, the lotteries are relatively small compared to the stocks. However, the large jackpot lotteries can still impact trading activity through behavioral channels, and are at the center of our study. 


\section{How does lottery influence trading activity?}

Our hypothesis is that some individual investors treat stock market as an alternative gambling venue. A large jackpot lottery represents a salient and attractive opportunity to some individual investors, who have high propensity to gamble in the stock market. Therefore, participating in such a lottery can be a substitute for stock trading as it satisfies their craving for gambling. To test the hypothesis, we use a series of large jackpot lotteries to examine this substitution effect by addressing the following five questions: Does the presence of large lotteries reduce shares traded for stocks which manifest greater gambling desire on the part of individual investors? Does trading activity of stocks with lottery features decline on large lottery jackpot days? How strong is the substitution effect between lottery and shares traded, as the jackpot increases? Do lotteries impact firm-level trading activities, and is the effect also discernible at the aggregate market level? Our results are important as they shed light on possible gambling motive for trading by individual investors and the impact of such motive.

\subsection{Lottery reduces trading activity of stocks preferred by individual investors}

Stemming from the fact that large jackpots often attract media coverage, they become a salient form of gambling alternative to stock trading among some investors. Therefore, we initially focus on lottery drawings with jackpots larger than 500 million TWD (around 15 million U.S. dollars), the 90th percentile of the jackpot distribution. Via such a specification of jackpots, we have a series of natural experiments, since (i) a large jackpot is a pure outcome of probability, (ii) it is unlikely to be driven by factors that affect the stock market, and (iii) it is improbable that lower trading of stocks on a particular day can meaningfully raise the jackpot for that day. It is the setting of repeated natural experiments on individual trading that differentiates our lottery study from the existing empirical literature.

First, we consider proxies for a set of stocks which are favored by individual investors, instead of institutional investors. Intuitively, the substitution effect between lottery and stock is likely to be concentrated among certain types of stocks. Our motivation is to show that when gambling needs do 
sway the action of individual investors, the size of the lottery jackpot can have a differential impact on the trading of stocks.

To build on the above theme, we construct four yardsticks of how much a certain stock type is preferred, or more often traded by individual investors.

- Individual trading fraction: Number of shares traded by individual investors divided by the total number of shares traded. If a stock's average trading fraction between day $t-1$ to $t-22$ is top (bottom) 30th percentile, we classify this stock as a high (low) individual trading fraction stock on date $t$. Then, we sum up the number of shares traded across all stocks in each of the three groups, and label them as high $(H)$, medium $(M)$, and low $(L)$. We repeat this approach each day in the sample, and construct the corresponding time series.

- Market capitalization: Share price of a stock multiplied by the number of shares outstanding. Stocks with high market capitalization on date $t$ are those stocks which fall in the top 30th percentile of average capitalization between day $t-1$ to $t-22$. The low capitalization stocks are analogously defined.

- Past returns: Measured by the 22 day average return between day $t-1$ to $t-22$. Stocks with high (low) past returns on date $t$ are those stocks whose average returns fall in the top (bottom) 30th percentile.

- Past turnover: Number of shares traded on day $t$ divided by the shares outstanding in a stock. Stocks with high (low) turnover on date $t$ are those stocks which appear in the top (bottom) 30 th percentile of turnover between day $t-1$ to $t-22$.

Our proxies for stock types that are preferred by individual investors are in line with earlier studies, for example, Gompers and Metrick (2001), who observe that institutional investors are more disposed toward stocks that are larger and more liquid, and with relatively low past returns (see also Hirshleifer (2001) and Foucault, Sraer, and Thesmar (2010)). Falkenstein (1996) likewise shows that mutual funds prefer stocks with high visibility and low transaction costs. 
Consider the following generic empirical specification:

$$
\log \left(V_{p, t}\right)=\beta_{0}+\beta_{p, 1} D_{t}^{\text {Jackpot }}+\beta_{p, 2} \log \left(\bar{V}_{p,[t-1 \rightarrow t-22]}\right)+\text { controls }+\varepsilon_{p, t}, \quad \text { for } p=H, M, L,
$$

where $V_{p, t}$ is the number of shares traded for a stock portfolio sharing high, medium, and low characteristics (i.e., $p=H, M, L$ ) respectively. In equation (1), $\bar{V}_{p,[t-1 \rightarrow t-22]}$ is the average of lagged trading activities between day $t-1$ to $t-22$ pertaining to the stock characteristic. We add the lagged terms $\bar{V}_{p,[t-1 \rightarrow t-22]}$ to control for possible persistence in trading activity. We also include two sets of control variables. The first set are four day of the week dummy variables, with Friday as the base. These dummy variables can capture the intra-week trading pattern, e.g., Lakonishok and Maberly (1990). The second set are two macroeconomic variables, the monthly unemployment rate and the quarterly GDP growth rate, to control for potential impact of the macroeconomic conditions on stock trading. ${ }^{3} \varepsilon_{t}$ is a zero-mean disturbance term.

At the heart of our approach is $D_{t}^{\text {Jackpot }}$, which represents a dummy variable for a large jackpot lottery and equals one when the cumulated prize is larger than 500 million TWD, and zero otherwise. One may view the large jackpot dummy as an instrument when (i) the investor's need for gambling is satisfied by buying lottery, and (ii) the investor's gambling desire is tilted towards certain stocks, for instance, those preferred by individual investors, and (iii) there is a substitution effect between lottery and those stocks among some investors. Through equation (1), we investigate whether shares traded on day $t$ are affected by the large jackpot on the same day.

Histogram evidence (not reported for brevity) confirms that while the level of the shares traded are skewed to the right, the empirical distribution of the log counterpart is closer to normal. Moreover, visual inspection of the plots of log variables suggests the time series are also stationary. Still, to substantiate that our empirical specifications do not suffer from a near unit root problem, we have performed the Phillips and Perron (1988) unit root test on the number of shares traded. The null hypothesis of a unit root is rejected at $1 \%$ confidence level with a $t$-statistic of -6.80 (the critical value is -3.46$)$.

Some core lessons can be learned based on the regression coefficients and the $p$-values reported

\footnotetext{
${ }^{3}$ We thank the referees for suggesting these control variables.
} 
in Table 3. Taking into consideration potential econometric concerns associated with the time-series properties of shares traded, we display the two-sided $p$-values for the coefficients based on the Newey and West (1987) heteroscedasticity and autocorrelation consistent (HAC) covariance matrix estimator. Our procedure relies on the Bartlett kernel and no prewhitening. Throughout, to gauge the statistical significance of the estimated coefficients in specification (1), we use an input of 7 for the lag length. This input is determined by the number of observations (i.e., 1,989) raised to the power $1 / 4$, as is often suggested, for instance, in Greene (2007). For brevity, we do not report the coefficients before the two sets of control variables in equation (1).

When we classify stocks according to high individual trading fraction between day $t-1$ to $t-22$ (see Panel A of Table 3), its number of shares traded by individual investors declines by $6.8 \%$ on a lottery drawing day with a large jackpot. Given the two-sided $p$-value of 0.020 , one can reject the null hypothesis that the lottery has zero effect on the shares traded. In the other extreme, namely those stocks that are least sought after by individual investors, one can observe an attenuation in the negative lottery impact. With a $p$-value of 0.644 , the effect is statistically indistinguishable from zero. In sum, stocks whose trading activity is dominated by individual investors experience a deterioration in shares traded when the lottery jackpot is large.

A similar overall picture is obtained when considering stocks classified by market capitalization (Panel B of Table 3). In particular, the coefficient on the large jackpot dummy is $-7.4 \%$ and statistically significant ( $p$-value is 0.016 ) for low capitalization stocks, while the effect is statistically insignificant ( $p$-value is 0.149 ) for large capitalization stocks. Accordingly, our results support a more pronounced and statistically reliable effect of large lottery on trading activities connected with low capitalization stocks. These results appear compatible with the notion that behavioral attributes of individual investors can disproportionately impact low capitalization stocks.

For those stocks falling in the high past returns category, the reduction in trading activity is of the order of $-10.9 \%$ ( $p$-value is 0.001 ) and strongest among all our proxies. In contrast, for stocks with the lowest past returns category, the counterpart coefficient is positive but statistically indistinguishable from zero (Panel C of Table 3). Equally important, and uniformly consistent with the above findings, Panel D of Table 3 implies that stocks with high past turnover are more affected 
by lottery with a significant decline of $6.0 \%$, compared with an insignificant $5.7 \%$ for stocks with low past turnover. ${ }^{4}$

Both results, namely, from high past returns and high past turnover, concur with the predictions of individual investor preference [[attention grabbing]]: if a stock has performed well, or has been actively traded in the past month, it spurs more individual trading, as documented in Barber and Odean (2008). Therefore, such stock's trading declines more by the presence of a large jackpot lottery, as substantiated in Table 3.

Summarizing our findings from this part of the investigation, the effect of large jackpot lotteries is stronger among stocks with (i) high individual trading fraction, (ii) low market capitalization, (iii) high past returns, and (iv) high past turnover. The documented substitution effect between lottery and stock is related to studies, including, for example, Loughran and Schultz (2004), who find that aggregate volume in locally headquartered stocks falls $17 \%$ in blizzard-struck cities. Shive (2010) uses large power outages as a natural experiment and finds that turnover in the median stock falls $23 \%$ during a local blackout.

In an approach resembling ours, Jacobs and Weber (2010) exploit regional holidays in Germany as a natural experiment in investor distraction; they show that holidays affect stock-level turnover, and they attribute their finding to local bias among investors. Instead, our channel is rooted in the combination of the substitution effect between lottery and stock, and a preference for certain types of stocks by individual investors. We now proceed to strengthen our evidence from yet another perspective.

\subsection{Trading in stocks with lottery features is adversely impacted by lottery jackpot}

Relying on theories from behavioral economics and finance (e.g., Tversky and Kahneman (1992), Golec and Tamarkin (1998), and Barberis and Huang (2008)), we now investigate the link between

\footnotetext{
${ }^{4}$ Reported in the final column are the $p$-values for the null hypothesis that the regression coefficients are jointly equal to zero. The joint $p$-values from the estimations are all below 0.050 . The variable $\bar{V}_{p,[t-1 \rightarrow t-22]}$ is positive and strongly significant. With the goodness-of-fit adjusted $R^{2}$ of the regressions close to $50 \%$, the fit of the estimations is reasonable.
} 
investors' preference for stocks with lottery features, trading activity, and lottery jackpot. Specifically, we pose the following question: How strong is the impact of a large jackpot lottery on shares traded of stocks with lottery features?

To answer this question, we construct three surrogates for stocks with lottery features, specifically stock return volatility, stock return skewness, and stock price, as essentially suggested in the previous studies of French, Schwert, and Stambaugh (1987), Campbell, Lettau, Malkiel, and Xu (2001), Harvey and Siddique (2000), Bakshi and Madan (2006), and Kumar (2009). Here we are also guided by the feature that individual stocks, especially in emerging markets, often have high idiosyncratic return components and, hence, a close correspondence exists between total return volatility and skewness and their idiosyncratic counterparts (see, among others, Bakshi, Kapadia, and Madan (2003), Ang, Hodrick, Xing, and Zhang (2009), and Bekaert, Hodrick, and Zhang (2010)).

Continuing, we construct the return volatility of a stock each day as its past 22 day return quadratic variation. Return skewness of a stock each day is computed based on the past six month's daily returns. The use of a longer history to compute skewness has been recommended by Kim and White (2004) and Bai and Ng (2005), and is consistent with the approach taken by Kumar (2009). The stock price is computed based on its past 22 day average price level.

We compute the volatility, skewness, and price of all the stocks in our sample each day, and then bin available stocks into three groups, respectively representing high (top 30th percentile), medium, and low (bottom 30th percentile) volatility skewness, and price stocks. For each group, we compute the sum total of shares traded and then build the time series of shares traded. Stocks with high dispersion and highly (positively) skewed returns are important to the studies of Mitton and Vorkink (2007), Boyer, Mitton, and Vorkink (2010), Kumar (2009), Bali, Cakici, and Whitelaw (2010), and to the economic theory of Barberis and Huang (2008).

Performing regressions analogous to those in specification (1), we report the results in Table 4. The results are informative from theoretical and empirical perspectives. First, trading activity of stocks exhibiting high return volatility falls by $7.4 \%$ (the $p$-value is 0.002 ), whereas the effect of lottery for stocks with low volatility is statistically insignificant (the $p$-value is 0.617 ). At the same time, the tabulated results indicate that trading activity of stocks with high (i.e., positive) return 
skewness declines more on large jackpot days compared to stocks with low skewness. Similarly, trading activity of low price stocks decreases more on large jackpot days compared to high price stocks. $^{5}$

Overall, the negative lottery impact is consistent with the view that buying lottery with a large jackpot serves as a substitute for stock trading because it satisfies individual investors' craving for gambling. Our empirical setting also captures the idea that the presence of a large lottery offering can translate into lower trading activity for stocks preferred by individual investors and stocks with lottery features.

Combining the results from Tables 3 and 4, two other points are worthy of further emphasis. First, using a natural experiment to tackle the concern of reverse causality, or endogeneity, has been widely adopted in labor and development economics, and in finance. See, among others, Landry, Lange, List, Price, and Rupp (2009), Duflo, Kremer, and Robinson (2008), Bittlingmayer (2002), Fishe and Robe (2004), Chari and Henry (2005), Gan (2007), and Foucault, Sraer, and Thesmar (2010). Second, isolating the trading activities by individual investors, as opposed to total shares traded, can better identify the channel of the substitution effect, i.e. individual investors' gambling needs.

\subsection{The substitution effect is monotonic in size of the lottery jackpot}

One concern is that the 500 million TWD cutoff of a large jackpot might be arbitrary. To accommodate this concern, we alter our specification in equation (1) to consider alternative threshold levels of lottery size of 400, 600, and 700 million TWD, which respectively represent the 85th, 92nd, and 95th percentile of the jackpot distribution. When the lottery jackpot increases, it translates into fewer jackpot day dummies but often attracts greater media coverage.

Rather than report all the coefficient estimates, we use Figure 1 to convey the most essential

\footnotetext{
${ }^{5}$ Our inference has so far rested on the $p$-values for the lottery dummy in Table 3 and 4 . If we adopt the dependent variable to be the log difference in shares traded of high and low grouping of a characteristic, while using the log difference of the average past trading activity of the high and low grouping as the control, the results are mostly in tandem with those reported. The $p$-values on the lottery dummy are smaller than 0.050 for individual trading fraction, past returns, and return volatility, thereby dispensing the need to report these results in parallel.
} 
point of this exercise. The gist is that when the estimated coefficients on the jackpot dummy are plotted against the size of the jackpot, respectively for each stock type studied in Tables 3 and 4, it reveals a monotonically declining pattern.

[Figure 1 about here.]

Even though not tabulated, there are $20 p$-values (out of 24 total) that are below 0.050 , and all $24 p$-values are below 0.100 , testifying to the strength of the monotonicity of the substitution effect between lottery and shares traded. The effect is also asymmetric across stock types. In particular, for high past return stocks, the negative impact of lottery gets more pronounced, from $-8.7 \%$ to $-13.1 \%$, as the jackpot increases from 400 million to 700 million TWD. A similar strong effect is validated for stocks with high return volatility and high return skewness.

The takeaway is that the substitution between lottery and stock among some individual investors is more intimately linked as the jackpot increases. The documented monotonic pattern is not at odds with behavioral arguments, since a larger jackpot is more attractive and salient, and the lottery-stock substitution is prevalent only among some types of stocks.

\subsection{Lottery negatively impacts trading activity at the firm level}

Our thrust here is to propose firm-level regressions with trading activities, which control for changes in the composition of firms that might otherwise confound tests that rely on aggregate trading activities. Some cross-sectional differences in lottery effects could get washed away under aggregation. An additional advantage of individual firm regression is that we can simultaneously control for the past trading activity of the firm as well as that of the market.

Specifically, the dependent variable in each firm-level regression is its trading activity by individual investors. That is, for each stock $i$, we perform the following time-series regression for its own trading activity $V_{i, t}$,

$$
\begin{aligned}
\log \left(V_{i, t}\right)= & \beta_{0, i}+\beta_{1, i} D_{t}^{\text {Jackpot }}+\beta_{2, i} \log \left(\bar{V}_{i,[t-1 \rightarrow t-22]}\right) \\
& +\beta_{3, i} \log \left(\bar{V}_{m,[t-1 \rightarrow t-22]}\right)+\text { controls }+\varepsilon_{i, t}, \quad \text { for } i=1, \ldots, I .
\end{aligned}
$$


The explanatory variables are a large lottery dummy $D_{t}^{\text {Jackpot }}$ (see equation (1)),

$\bar{V}_{i,[t-1 \rightarrow t-22]}$ is the average of lagged trading activities between day $t-1$ to $t-22$, and $\bar{V}_{m,[t-1 \rightarrow t-22]}$ represents the average of lagged market trading activity by individual investors between day $t-1$ to $t-22$. The control variables include day of the week dummies, monthly unemployment rate, and quarterly GDP growth rate. $\varepsilon_{i, t}$ denotes a zero-mean disturbance term. Our motivation for including both $\bar{V}_{m,[t-1 \rightarrow t-22]}$ and $\bar{V}_{i,[t-1 \rightarrow t-22]}$ is to control for the persistence of trading activity and potential unobserved firm heterogeneity.

To measure the impact of lottery on firm trading activity, we perform the estimation (2) for each firm separately, keeping in mind the concerns of Petersen (2009) and Skoulakis (2009) on the cross-sectional correlation in standard errors. Moreover, guided by frugality of presentation, we summarize our results from three perspectives. First, we report the average sensitivity to assess the mean effect. Second, we report the $t$-statistic for the average sensitivity, under the assumption that sensitivity coefficients are i.i.d. across firms. Finally, we count the number of firms that share the same sign as the average sensitivity, and have $p$-values less than 0.050 or 0.100 according to the Newey and West (1987) HAC estimator. The number of $\beta_{1, i}<0$ coefficients with significant $p$-value in equation (2) bears critically on our analysis.

At the outset, observe that Table 5 shows that the large lottery dummy has a negative impact on trading activity by individual investors. What is noteworthy is that the number of shares traded drops, on average, by $7.4 \%$ when there is a large jackpot lottery drawing on the same day (see the row marked Avg. for the Unrestricted model), mirroring our previous findings. The $t$-statistic on the average sensitivity is $-18.17 \%$, as seen from the row marked " $t$-stat." The negative average impact of lottery maintains its significance even after we omit the control for the average of the lagged number of shares traded by individuals in the market.

Equally important, there are 108 firms (see the row marked \#, p-val.<0.05) that support a negative coefficient on $D_{t}^{\text {Jackpot }}$ in the unrestricted model in equation (2), and yet have a $p$-value less than 0.050 associated with $\beta_{1, i}$ according to the Newey and West (1987) HAC estimator. The number of firms rises to 164 when the significance criterion is relaxed to $p$-value less than 0.100 .

A common conclusion to draw based on Tables 3, 4, and 5 is that both the effect for certain 
types of stocks and the average firm-level effect are strongly significant. When the lottery jackpot is large, this alternative form of gambling becomes more attractive and salient among some individual investors, and accordingly affects their trading. While one may be concerned that our results might be affected by some other exogenous events in the market, the concern is alleviated by two considerations. First, it is unlikely that those events are correlated with the lottery drawings with large jackpots, as a large jackpot is solely dictated by probability. Second, the effect of lottery permeates to the trading activity of a sizable number of individual firms.

\subsection{The effect of lottery jackpot is also affirmed in aggregate trading activity}

Table 6 presents the market-level regression results when the dependent variable is the aggregate trading activities of individual investors. The crucial result to be garnered from Panel A of Table 6 is that large lottery exerts a negative impact on shares traded in the aggregate. Essentially, we find that the number of shares traded decreases strongly by $5.1 \%$ (the two-sided $p$-value is 0.049 ).

To put the above results in perspective, a 5.1\% reduction in trading activity by individual investors corresponds to a 99.3 million reduction in share trading (given that the median of daily shares traded is 1.948 billion; see Table 2), thereby leading to a 2.1 billion TWD trading value impact (given the median per share price of 21 TWD; see Table 2). Thus, the magnitudes of the coefficients on $D_{t}^{\text {Jackpot }}$ are both economically and statistically significant.

The question to ask now is: Do our results stay intact if one adopts alternative measures of aggregate trading activity? We address this question in two ways, where we first employ the log of the value traded as a proxy for trading activities (from TSE). The presence of a large jackpot lottery significantly reduces the amount of trading activity in the stock market, especially for individual investors, broadly reflecting our findings from Panel A of Table 6. The regression, in Panel B of Table 6, yields a magnitude on the jackpot dummy coefficient of $-6.0 \%$ ( $p$-value of 0.028 ). Probing further with the log of the turnover as a proxy for trading activity, we find, in Panel C of Table 6, an analogous effect, with a coefficient of $-5.2 \%$ ( $p$-value of 0.042 ). Our evidence corroborates that the documented impact of lottery on trading activity is likely an intrinsic property of our sample. ${ }^{6}$

\footnotetext{
${ }^{6}$ In general, there is a high correlation between trading by individual investors in the market and the total trading in
} 
Given that the decrease in trading value is more than four-fold larger than the large jackpot threshold of 500 million TWD, or equivalently 2.5 times larger than the conditional average (i.e, 840 million TWD) of jackpots above the threshold, the substitution effect between lottery and stock is predominantly about investor switching the gambling venues from stock to lottery and not about reverse causation.

\subsection{Robustness checks impart a qualitatively similar picture}

How robust are our results over subsamples and an alternative measure of a salient and attractive lottery? Germane to the first question is the feature that the distribution of large jackpot lottery drawings over the years is not entirely uniform. Although we have controlled for the macroeconomic conditions in our main regression, one may be still concerned that there are relatively more large jackpot lotteries in 2002, 2008, and 2009. ${ }^{7}$ Regarding the second question, we use the lottery sales, in a similar fashion as the jackpot, to identify the substitution effect between lottery and stock.

We repeat our main analysis in Section 3.1 and Section 3.2 over two subsample periods. Panel A and Panel B of Table 7 reports the estimation results for our daily sample over the years 2002 to 2007 and 2003 to 2009, respectively. We exclude 2008 and 2009 in Panel A because there are more large jackpot lotteries (37 and 32) in these two years. These two years also represent extraordinary macroeconomic conditions. Similarly, Panel B excludes the year of 2002, which has more large jackpots (27) and coincides with a period of high unemployment rate following a recession. We

focus on stock types in Table 3, i.e. high individual trading fraction, low market capitalization, high past return, and high past turnover, to save on space, and the results confirm a qualitatively similar negative lottery impact on stock trading. For example, the number of shares traded among high individual trading fraction stocks decreases by $7.5 \%$ on a large jackpot drawing day.

We repeat the analysis in Section 3.3 with lottery sales and presents the results in Figure 2. We plot the estimated coefficients on the large sales dummy against the size of the sales, respectively for stock types studied in Tables 3 and 4 . Figure 2 reveals a monotonically declining pattern, similar to the market. The respective correlations are $0.94,0.85$, and 0.92 for the shares traded, the value traded, and turnover.

${ }^{7}$ We would like to thank an anonymous referee to point this out. 
that in Figure 1. Collectively, the documented substitution effect between lottery and stock appears structurally stable and is not an artifact of the sample.

[Figure 2 about here.]

\section{Concluding remarks}

In this paper, we take advantage of multiple natural experiments of large jackpot lotteries in Taiwan to show that buying lottery with a large jackpot can be a substitute for stock trading. We establish five distinct empirical findings that are consistent with our hypothesis that some individual investors view trading stocks as an opportunity to gamble.

First, when the jackpot exceeds 500 million Taiwan dollars (about 15 million U.S. dollars), the number of shares traded by individual investors decreases by about $7 \%$ among stocks with high individual trading fraction, low market capitalization, high past returns, and high past turnover. For stocks with low individual trading fraction, high market capitalization, low past returns, and low past turnover, the effect of lottery on trading activity is statistically indistinguishable from zero. Second, our approach reveals that the substitution effect is stronger among stocks with lottery features. Specifically, a 7\% decline in shares traded is observed among stocks with high return volatility and skewness.

Third, we also find that the magnitude of the documented substitution effect increases monotonically with the jackpot. Fourth, the reaction of firm-level trading activity by individual investors is negative to lottery drawings, and is statistically significant for a sizable number of firms. Finally, the aggregate number of shares traded by individual investors declines by around $5 \%$ with lottery offerings, and this effect is both economically and statistically significant.

In sum, under the framework of repeated natural experiments, our study offers compelling evidence that some individual investors substitute stock trading for lottery gambling. 


\section{References}

Ang, A., Hodrick, R., Xing, Y., Zhang, X., 2009. High idiosyncratic volatility and low returns: International and further U.S. evidence. Journal of Financial Economics 91, 1-23.

Bai, J., Ng, S., 2005. Tests of skewness, kurtosis, and normality in time series data. Journal of Business and Economics Statistics 23, 49-60.

Baker, M., Wurgler, J., 2007. Investor sentiment in the stock market. Journal of Economic Perspectives $21,129-151$.

Bakshi, G., Kapadia, N., Madan, D., 2003. Stock return characteristics, skew laws, and the differential pricing of individual equity options. Review of Financial Studies 16, 101-143.

Bakshi, G., Madan, D., 2006. A theory of volatility spreads. Management Science 52, 1945-1956.

Bali, T., Cakici, N., Whitelaw, R., 2010. Maxing out: Stocks as lotteries and the cross-section of expected returns. Journal of Financial Economics (forthcoming).

Barber, B., Lee, Y.-T., Liu, Y.-J., Odean, T., 2009. Just how much do individual investors lose by trading?. Review of Financial Studies 22, 609-632.

Barber, B., Odean, T., 2008. All that glitters: The effect of attention and news on the buying behavior of individual and institutional investors. Review of Financial Studies 21, 785-818.

Barberis, N., Huang, M., 2008. Stocks as lotteries: The implications of probability weighting for security prices. American Economic Review 98, 2066-2100.

Bekaert, G., Hodrick, R., Zhang, X., 2010. Aggregate idiosyncratic volatility. Unpublished working paper. NBER\#16058.

Bittlingmayer, G., 2002. Output, stock volatility, and political uncertainty in a natural experiment: Germany, 1880-1940. Journal of Finance 53, 2243-2257.

Boyer, B., Mitton, T., Vorkink, K., 2010. Expected idiosyncratic skewness. Review of Financial Studies 23, 169-202.

Brenner, R., Brenner, G., 1990. Gambling and Speculation. Cambridge University Press, Cambridge, UK. 
Campbell, J., Lettau, M., Malkiel, B., Xu, Y., 2001. Have individual stocks become more volatile? An empirical exploration of idiosyncratic risk. Journal of Finance 56, 1-43.

Chari, A., Henry, P., 2005. Risk sharing and asset prices: Evidence from a natural experiment. Journal of Finance 59, 1295-1324.

Chordia, T., Roll, R., Subrahmanyam, A., 2010. Recent trends in trading activity. Unpublished working paper. University of Califonia at Los Angeles.

Dorn, D., Sengmueller, P., 2009. Trading as entertainment?. Management Science 55, 591-603.

Duflo, E., Kremer, M., Robinson, J., 2008. How high are rates of return to fertilizer? Evidence from field experiments in Kenya. American Economic Review 98, 482-488.

Falkenstein, E., 1996. Preferences for stock characteristics as revealed by mutual fund portfolio holdings. Journal of Finance 51, 111-135.

Fishe, R., Robe, M., 2004. The impact of illegal insider trading in dealer and specialist markets: Evidence from a natural experiment. Journal of Financial Economics 71, 461-488.

Foucault, T., Sraer, D., Thesmar, D., 2010. Individual investors and volatility. Unpublished working paper. HEC Paris and University of California at Berkeley.

French, K., Schwert, W., Stambaugh, R., 1987. Expected stock returns and volatility. Journal of Financial Economics 19, 3-29.

Gan, J., 2007. Collateral, debt capacity, and corporate investment: Evidence from a natural experiment. Journal of Financial Economics 85, 709-734.

Golec, J., Tamarkin, M., 1998. Bettors love skewness, not risk, at the horse track. Journal of Political Economy 106, 205-225.

Gompers, P., Metrick, A., 2001. Institutional investors and equity prices. Quarterly Journal of Economics 116, 229-259.

Greene, W., 2007. Econometric Analysis. Prentice Hall, Upper Saddle River, New Jersey.

Grinblatt, M., Keloharju, M., 2009. Sensation seeking, overconfidence, and trading activity. Journal of Finance 64, 549-576. 
Harvey, C., Siddique, A., 2000. Conditional skewness in asset pricing tests. Journal of Finance 55, $1263-1295$.

Hirshleifer, D., 2001. Investor psychology. Journal of Finance 56, 1533-1597.

Jacobs, H., Weber, M., 2010. The market impact of local bias: Evidence from a natural experiment in the German stock market. Unpublished working paper. University of Mannheim.

Kim, T., White, H., 2004. On more robust estimation of skewness and kurtosis: Simulation and application to the S\&P 500 index. Finance Letters 1(1), 56-73.

Kumar, A., 2009. Who gambles in the stock market?. Journal of Finance 64, 1889-1933.

Lakonishok, J., Maberly, E., 1990. The weekend effect: Trading patterns of individual and institutional investors. The Journal of Finance 45, pp. 231-243.

Landry, C., Lange, A., List, J., Price, M., Rupp, N., 2009. Is a donor in hand better than two in the bush? Evidence from a natural field experiment. American Economic Review (forthcoming).

Loughran, T., Schultz, P., 2004. Weather, stock returns, and the impact of localized trading behavior. Journal of Financial and Quantitative Analysis 39, 343-364.

Mitton, T., Vorkink, K., 2007. Equilibrium underdiversification and preference for skewness. Review of Financial Studies 20, 1255-1288.

Newey, W., West, K., 1987. A simple, positive semi-definite, heteroskedasticity and autocorrelation consistent covariance matrix. Econometrica 55, 703-708.

Petersen, M., 2009. Estimating standard errors in finance panel data sets: Comparing approaches. Review of Financial Studies 22, 435-480.

Phillips, P., Perron, P., 1988. Testing for a unit root in time series regression. Biometrika 75, 335346.

Shive, S., 2010. How do local investors affect prices? Power outages as a natural experiment. Unpublished working paper. University of Notre Dame.

Skoulakis, G., 2009. Panel data inference in finance: Least squares versus Fama-McBeth. Unpublished working paper. University of Maryland. 
Statman, M., 2002. Lottery players/stock traders. Financial Analysts Journal 58, 14-21.

Tversky, A., Kahneman, D., 1992. Advances in prospect theory: Cumulative representation of uncertainty. Journal of Risk and Uncertainty 5, 297-323. 
Table 1 Lottery jackpot size descriptive statistics

\begin{tabular}{|c|c|c|c|c|c|c|c|c|}
\hline \multirow[b]{2}{*}{ Year } & \multirow[b]{2}{*}{$\begin{array}{c}\text { Number of } \\
\text { lottery } \\
\text { drawings }\end{array}$} & \multirow[b]{2}{*}{$\begin{array}{c}\text { Number of } \\
\text { drawings } \\
\text { (jackpot } \\
\geq 500 \mathrm{~m} \text { ) }\end{array}$} & \multicolumn{6}{|c|}{ Jackpot size (in millions of TWD) } \\
\hline & & & Mean & Std. & Min. & $\begin{array}{c}50 \text { th } \\
\text { percentile }\end{array}$ & $\begin{array}{c}\text { 90th } \\
\text { percentile }\end{array}$ & Max. \\
\hline All years & 1,495 & 163 & 255 & 267 & 23 & 178 & 529 & 2,930 \\
\hline 2002 & 99 & 27 & 470 & 238 & 284 & 379 & 698 & 1,823 \\
\hline 2003 & 104 & 11 & 341 & 182 & 195 & 287 & 522 & 1,329 \\
\hline 2004 & 209 & 16 & 257 & 238 & 84 & 198 & 430 & 2,097 \\
\hline 2005 & 208 & 14 & 218 & 220 & 65 & 149 & 431 & 1,732 \\
\hline 2006 & 248 & 15 & 183 & 283 & 42 & 88 & 378 & 2,930 \\
\hline 2007 & 209 & 11 & 147 & 202 & 23 & 77 & 369 & 1,799 \\
\hline 2008 & 209 & 37 & 317 & 361 & 27 & 195 & 770 & 2,138 \\
\hline 2009 & 209 & 32 & 276 & 216 & 32 & 198 & 599 & 1,209 \\
\hline
\end{tabular}

Notes. Reported are the descriptive statistics for the lottery jackpot from January 22, 2002, to December 31, 2009. There are a total of 1,495 lottery drawings, and reported values are in millions of Taiwan dollars (TWD). Reported also are the number of lottery drawings with a jackpot larger than 500 million TWD and the number of lottery drawings with a jackpot larger than 500 million TWD on a trading day. Displayed are mean, standard deviation (denoted Std.), minimum (denoted Min.), 50th percentile, 90th percentile, and maximum (denoted Max.) of the jackpot. 


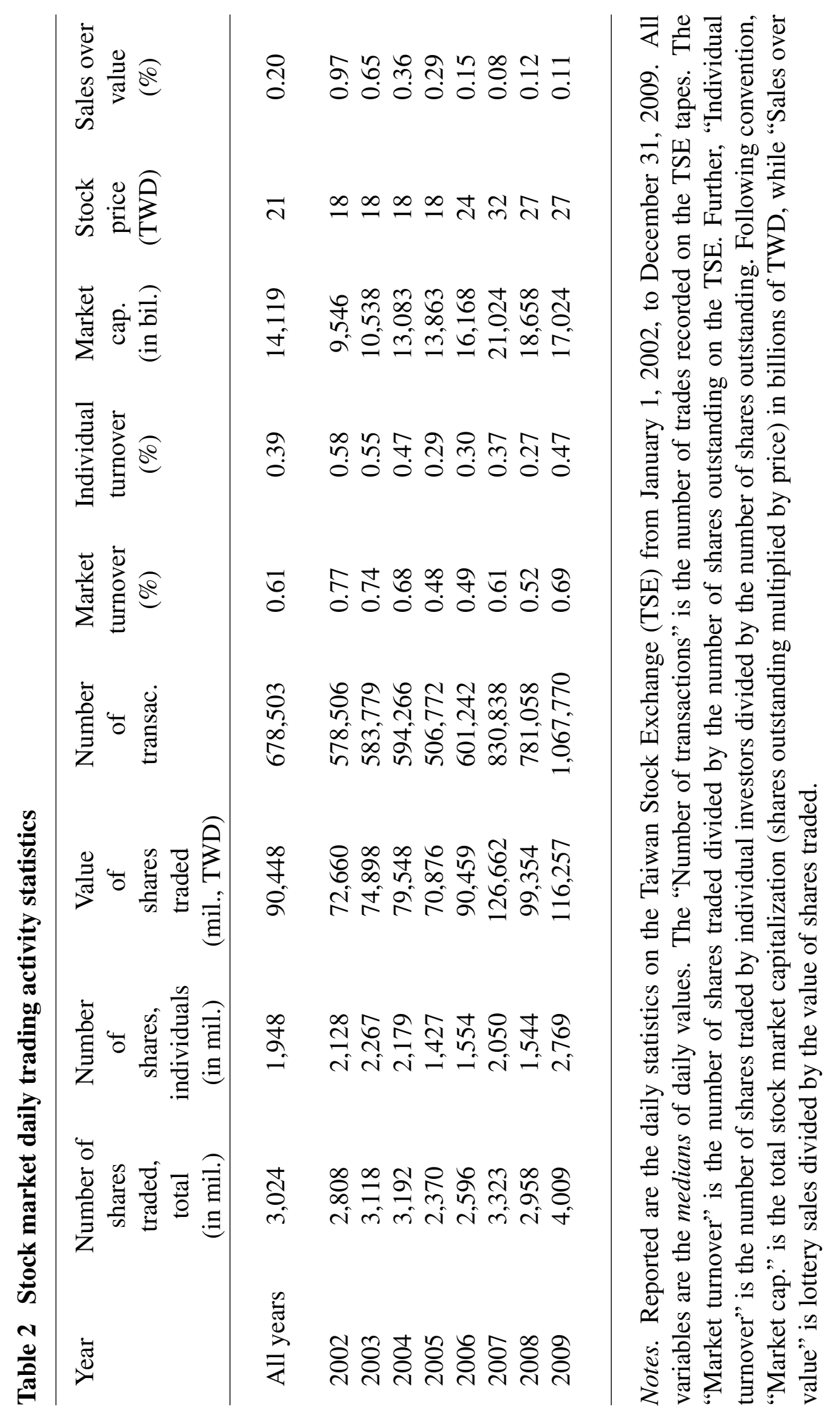


Table 3 Impact of large jackpot on number of shares traded in stocks favored by individual investors

\begin{tabular}{|c|c|c|c|c|c|}
\hline $\begin{array}{l}\text { Dependent variable: } \\
\text { Log of shares traded } \\
\text { by individual investors }\end{array}$ & $\begin{array}{l}\text { Large } \\
\text { jackpot } \\
\text { dummy }\end{array}$ & $\begin{array}{c}\text { Trading } \\
\text { activity } \\
{[-1 \rightarrow-22]} \\
\end{array}$ & Intercept & $\begin{array}{c}\bar{R}^{2} \\
\lfloor D W\rfloor\end{array}$ & $\begin{array}{c}\text { Joint } \\
p \text {-val. }\end{array}$ \\
\hline \multicolumn{6}{|l|}{ Panel A: Individual trading fraction stocks } \\
\hline High individual trading fraction stocks & $\begin{array}{l}-0.068 \\
(0.020)\end{array}$ & $\begin{array}{c}0.916 \\
(0.000)\end{array}$ & $\begin{array}{c}1.054 \\
(0.001)\end{array}$ & $\begin{array}{c}70.2 \% \\
|1.1|\end{array}$ & 0.000 \\
\hline Low individual trading fraction stocks & $\begin{array}{l}-0.013 \\
(0.644)\end{array}$ & $\begin{array}{c}0.839 \\
(0.000)\end{array}$ & $\begin{array}{c}1.990 \\
(0.000)\end{array}$ & $\begin{array}{c}55.7 \% \\
\lfloor 1.4\rfloor\end{array}$ & 0.000 \\
\hline \multicolumn{6}{|l|}{ Panel B: Market capitalization } \\
\hline High market cap stocks & $\begin{array}{l}-0.038 \\
(0.149)\end{array}$ & $\begin{array}{c}0.870 \\
(0.000)\end{array}$ & $\begin{array}{c}1.672 \\
(0.000)\end{array}$ & $\begin{array}{c}60.5 \% \\
\lfloor 1.3\rfloor\end{array}$ & 0.000 \\
\hline Low market cap stocks & $\begin{array}{l}-0.074 \\
(0.016)\end{array}$ & $\begin{array}{c}0.918 \\
(0.000)\end{array}$ & $\begin{array}{c}0.848 \\
(0.003)\end{array}$ & $\begin{array}{l}71.8 \% \\
\lfloor 1.1\rfloor\end{array}$ & 0.000 \\
\hline \multicolumn{6}{|l|}{ Panel C: Past returns } \\
\hline High past return stocks & $\begin{array}{l}-0.109 \\
(0.001)\end{array}$ & $\begin{array}{c}0.885 \\
(0.000)\end{array}$ & $\begin{array}{c}1.456 \\
(0.000)\end{array}$ & $\begin{array}{c}61.6 \% \\
\lfloor 1.1\rfloor\end{array}$ & 0.000 \\
\hline Low past return stocks & $\begin{array}{c}0.041 \\
(0.161)\end{array}$ & $\begin{array}{c}0.726 \\
(0.000)\end{array}$ & $\begin{array}{c}3.301 \\
(0.000)\end{array}$ & $\begin{array}{c}35.7 \% \\
\lfloor 1.4\rfloor\end{array}$ & 0.000 \\
\hline \multicolumn{6}{|l|}{ Panel D: Past turnover } \\
\hline High past turnover stocks & $\begin{array}{l}-0.060 \\
(0.010)\end{array}$ & $\begin{array}{c}0.870 \\
(0.000)\end{array}$ & $\begin{array}{c}1.753 \\
(0.000)\end{array}$ & $\begin{array}{c}56.8 \% \\
\lfloor 1.3\rfloor\end{array}$ & 0.000 \\
\hline Low past turnover stocks & $\begin{array}{l}-0.057 \\
(0.154)\end{array}$ & $\begin{array}{c}0.899 \\
(0.000)\end{array}$ & $\begin{array}{c}0.954 \\
(0.000)\end{array}$ & $\begin{array}{c}66.1 \% \\
\lfloor 1.3\rfloor\end{array}$ & 0.000 \\
\hline
\end{tabular}

Notes. Estimation results are based on the specification $\log \left(V_{p, t}\right)=\beta_{0}+\beta_{p, 1} D_{t}^{\text {Jackpot }}+$ $\beta_{p, 2} \log \left(\bar{V}_{p,[t-1 \rightarrow t-22]}\right)+$ controls $+\varepsilon_{p, t}$, for $p=H, M, L$. The dependent variable is the log of the shares traded and the "large jackpot dummy" equals one if the jackpot size exceeds 500 million TWD. The control variables include day of the week dummies, monthly unemployment rate, and quarterly GDP growth rate. We measure the number of shares traded by individual investors in four ways, respectively, as (i) individual trading fraction, (ii) market capitalization, (iii) past returns, and (iv) past turnover. Each day, we divide the ordered distribution of stocks by the characteristic into three parts, each respectively representing 30\%, 40\%, and 30\% of the sample, based on their average value over day $t-1$ to $t-22$. The two-sided $p$-values (reported in parenthesis) are calculated using the Newey and West (1987) heteroscedasticity and autocorrelation consistent (HAC) covariance matrix estimator with lag length set to 7 (computed as the number of daily observations, 1,989, raised to the power $1 / 4) . \bar{R}^{2}$ is adjusted $R^{2}$, and the Durbin Watson statistic is shown as $\lfloor D W\rfloor$. We report the $p$-values for the null hypothesis that all the regression coefficients are jointly equal to zero. 
Table 4 Impact of large jackpot on number of shares traded by individual investors for stocks with lottery features

\begin{tabular}{|c|c|c|c|c|c|}
\hline $\begin{array}{l}\text { Dependent variable: } \\
\text { Log of shares traded } \\
\text { by individual investors }\end{array}$ & $\begin{array}{l}\text { Large } \\
\text { jackpot } \\
\text { dummy }\end{array}$ & $\begin{array}{c}\text { Trading } \\
\text { activity } \\
{[-1 \rightarrow-22]}\end{array}$ & Intercept & $\begin{array}{c}\bar{R}^{2} \\
\lfloor D W\rfloor\end{array}$ & $\begin{array}{l}\text { Joint } \\
p \text {-val. }\end{array}$ \\
\hline \multicolumn{6}{|l|}{ Panel A: Return volatility } \\
\hline High return volatility stocks & $\begin{array}{l}-0.074 \\
(0.002)\end{array}$ & $\begin{array}{c}0.881 \\
(0.000)\end{array}$ & $\begin{array}{c}1.569 \\
(0.000)\end{array}$ & $\begin{array}{c}60.2 \% \\
\lfloor 1.3\rfloor\end{array}$ & 0.000 \\
\hline Low return volatility stocks & $\begin{array}{l}-0.019 \\
(0.617)\end{array}$ & $\begin{array}{c}0.891 \\
(0.000)\end{array}$ & $\begin{array}{c}1.150 \\
(0.000)\end{array}$ & $\begin{array}{c}61.3 \% \\
\lfloor 1.3\rfloor\end{array}$ & 0.000 \\
\hline \multicolumn{6}{|l|}{ Panel B: Return skewness } \\
\hline High return skewness stocks & $\begin{array}{l}-0.066 \\
(0.054)\end{array}$ & $\begin{array}{c}0.885 \\
(0.000)\end{array}$ & $\begin{array}{c}1.426 \\
(0.000)\end{array}$ & $\begin{array}{c}59.5 \% \\
\lfloor 1.2\rfloor\end{array}$ & 0.000 \\
\hline Low return skewness stocks & $\begin{array}{l}-0.046 \\
(0.098)\end{array}$ & $\begin{array}{c}0.899 \\
(0.000)\end{array}$ & $\begin{array}{c}1.182 \\
(0.001)\end{array}$ & $\begin{array}{c}69.8 \% \\
\lfloor 1.3\rfloor\end{array}$ & 0.000 \\
\hline \multicolumn{6}{|l|}{ Panel C: Stock price } \\
\hline High price stocks & $\begin{array}{l}-0.037 \\
(0.134)\end{array}$ & $\begin{array}{c}0.860 \\
(0.000)\end{array}$ & $\begin{array}{c}1.775 \\
(0.000)\end{array}$ & $\begin{array}{c}54.1 \% \\
\lfloor 1.4\rfloor\end{array}$ & 0.000 \\
\hline Low price stocks & $\begin{array}{l}-0.055 \\
(0.101)\end{array}$ & $\begin{array}{c}0.898 \\
(0.000)\end{array}$ & $\begin{array}{c}1.225 \\
(0.000)\end{array}$ & $\begin{array}{c}66.9 \% \\
\lfloor 1.1\rfloor\end{array}$ & 0.000 \\
\hline
\end{tabular}

Notes. Estimation results are based on the specification $\log \left(V_{p, t}\right)=\beta_{0}+\beta_{p, 1} D_{t}^{\text {Jackpot }}+$ $\beta_{p, 2} \log \left(\bar{V}_{p,[t-1 \rightarrow t-22]}\right)+$ controls $+\varepsilon_{p, t}$, for $p=H, M, L$. The dependent variable is the log of the shares traded and the "large jackpot dummy" equals one if the jackpot size exceeds 500 million TWD. The control variables include day of the week dummies, monthly unemployment rate, and quarterly GDP growth rate. We measure the number of shares traded by individual investors in stocks with lottery features in three ways, respectively, as (i) return volatility, and (ii) return skewness, and (iii) stock price level. Each day, we divide the ordered distribution of stocks by the two lottery features into three parts, each respectively representing 30\%, 40\%, and $30 \%$ of the sample. Return volatility is calculated based on the past 22 trading day returns (following Campbell, Lettau, Malkiel, and Xu (2001)), while return skewness is calculated over the past six months (i.e., following Kumar (2009)). The two-sided $p$-values (reported in parenthesis) are calculated using the Newey and West (1987) heteroscedasticity and autocorrelation consistent (HAC) covariance matrix estimator with lag length set to 7 (computed as the number of daily observations, 1,989, raised to the power $1 / 4$ ). $\bar{R}^{2}$ is adjusted $R^{2}$, and the Durbin Watson statistic is shown as $\lfloor D W\rfloor$. We report the $p$-values for the null hypothesis that all the regression coefficients are jointly equal to zero. 
Table 5 Impact of large jackpot on the number of shares traded, firm-level evidence

\begin{tabular}{|c|c|c|c|}
\hline & & $\begin{array}{c}\text { Restricted } \\
\beta_{3, i} \equiv 0\end{array}$ & $\begin{array}{c}\text { Unrestricted } \\
\text { model }\end{array}$ \\
\hline Large jackpot lottery dummy & $\begin{array}{l}\text { Avg. } \\
t \text {-stat } \\
\#, p \text {-val. }<0.05 \\
\#, p \text {-val. }<0.10\end{array}$ & $\begin{array}{c}-0.085 \\
(-21.42) \\
\{121\} \\
\{184\}\end{array}$ & $\begin{array}{c}-0.074 \\
(-18.17) \\
\{108\} \\
\{164\}\end{array}$ \\
\hline $\begin{array}{l}\text { Log of average firm's daily number } \\
\text { of shares traded by individual } \\
\text { investors over }[-1 \rightarrow-22]\end{array}$ & $\begin{array}{l}\text { Avg. } \\
t \text {-stat } \\
\#, p \text {-val. }<0.05 \\
\#, p \text {-val. }<0.10\end{array}$ & $\begin{array}{c}0.784 \\
(144.02) \\
\{724\} \\
\{726\}\end{array}$ & $\begin{array}{c}0.727 \\
(100.43) \\
\{718\} \\
\{720\}\end{array}$ \\
\hline $\begin{array}{l}\text { Log of number of shares in market } \\
\text { traded by individual investors } \\
\text { over }[-1 \rightarrow-22]\end{array}$ & $\begin{array}{l}\text { Avg. } \\
t \text {-stat } \\
\#, p \text {-val. }<0.05 \\
\#, p \text {-val. }<0.10\end{array}$ & & $\begin{array}{c}0.284 \\
(23.76) \\
\{398\} \\
\{436\}\end{array}$ \\
\hline $\bar{R}^{2}, \mathrm{Avg}$ & & $43.7 \%$ & $44.7 \%$ \\
\hline Number of firms & & 734 & 734 \\
\hline
\end{tabular}

Notes. Estimation results are based on the specification $\log \left(V_{i, t}\right)=\beta_{0, i}+\beta_{1, i} D_{t}^{\text {Jackpot }}+$ $\beta_{2, i} \log \left(\bar{V}_{i,[t-1 \rightarrow t-22]}\right)+\beta_{3, i} \log \left(\bar{V}_{m,[t-1 \rightarrow t-22]}\right)+$ controls $+\varepsilon_{i, t}$, for $i=1, \ldots, I$. The dependent variable is the log of the firms' number of shares traded by individual investors. The large jackpot lottery dummy corresponds to a cumulative prize in excess of 500 million TWD. We control for the firm's average trading, and the market average trading, during $[-1 \rightarrow-22]$ prior to the lottery drawing day, day of the week dummies, monthly unemployment rate, and quarterly GDP growth rate. Reported are (i) average of the estimated coefficients, (ii) $t$-statistic on the average coefficient, under the assumption that the coefficients are distributed i.i.d, and (iii) \#, $p$-val. $<0.050$ (and \#, $p$ val. $<0.100)$, which corresponds to the number of coefficients with $p$-value less than $0.050(0.100)$, and with a sign that is of the average coefficient; these are reported in curly brackets, and are based on the Newey and West heteroscedasticity and autocorrelation consistent (HAC) covariance matrix estimator. 
Table 6 Impact of large jackpot on the aggregate trading behavior

\begin{tabular}{|c|c|c|c|c|c|}
\hline $\begin{array}{l}\text { Dependent } \\
\text { variable }\end{array}$ & $\begin{array}{l}\text { Large } \\
\text { jackpot } \\
\text { dummy }\end{array}$ & $\begin{array}{c}\text { Corresponding } \\
\text { trading activity } \\
\text { over }[-1 \rightarrow-22]\end{array}$ & Intercept & $\begin{array}{c}\bar{R}^{2} \\
\lfloor D W\rfloor\end{array}$ & $\begin{array}{l}\text { Joint } \\
p \text {-val }\end{array}$ \\
\hline $\begin{array}{l}\text { Panel A: Log of shares traded } \\
\text { Log of shares traded by individuals }\end{array}$ & $\begin{array}{l}-0.051 \\
(0.049)\end{array}$ & $\begin{array}{c}0.881 \\
(0.000)\end{array}$ & $\begin{array}{c}1.608 \\
(0.000)\end{array}$ & $\begin{array}{c}61.5 \% \\
\lfloor 1.3\rfloor\end{array}$ & 0.000 \\
\hline $\begin{array}{l}\text { Panel B: Log of value traded } \\
\text { Log of value traded by individuals }\end{array}$ & $\begin{array}{l}-0.060 \\
(0.028)\end{array}$ & $\begin{array}{c}0.929 \\
(0.000)\end{array}$ & $\begin{array}{l}1.210 \\
(0.004)\end{array}$ & $\begin{array}{l}67.5 \% \\
\lfloor 1.3\rfloor\end{array}$ & 0.000 \\
\hline $\begin{array}{l}\text { Panel C: Log of turnover } \\
\text { Log of turnover by individuals }\end{array}$ & $\begin{array}{l}-0.052 \\
(0.042)\end{array}$ & $\begin{array}{c}0.891 \\
(0.000)\end{array}$ & $\begin{array}{l}-0.249 \\
(0.013)\end{array}$ & $\begin{array}{c}67.5 \% \\
\lfloor 1.3\rfloor\end{array}$ & 0.000 \\
\hline
\end{tabular}

Notes. Here we perform the regression: $V_{m, t}=\beta_{0}+\beta_{1} D_{t}^{\text {Jackpot }}+\beta_{2} \bar{V}_{m,[t-1 \rightarrow t-22]}+$ controls $+\varepsilon_{t}$, where $V_{m, t}$ is either the $\log$ of shares traded in the aggregate (Panel A), the $\log$ of the total value traded (Panel B), or the log of the turnover (Panel C), all by individual investors. The "large jackpot dummy" equals one if the jackpot size exceeds 500 million TWD. $\bar{V}_{m,[t-1 \rightarrow t-22]}$ is the average trading of individual investors in the market during $[-1 \rightarrow-22]$ prior to the lottery drawing day. The control variables include four day of the week dummies, monthly unemployment rate, and quarterly GDP growth rate. The two-sided $p$-values (reported in parenthesis) are calculated using the Newey and West (1987) heteroscedasticity and autocorrelation consistent (HAC) covariance matrix estimator with lag length set to $7 . \bar{R}^{2}$ is adjusted $R^{2}$ and the number of daily observations used in each estimation is 1,989 . The Durbin Watson statistic is shown as $\lfloor D W\rfloor$. We report the $p$-values for the null hypothesis that all the regression coefficients are jointly equal to zero. 
Table 7 Impact of large jackpot on trading activity when using the 2002-2007 and 2003-2009 subsamples

\begin{tabular}{|c|c|c|c|c|c|}
\hline $\begin{array}{l}\text { Dependent variable: } \\
\text { Log of shares traded } \\
\text { by individual investors }\end{array}$ & $\begin{array}{l}\text { Large } \\
\text { jackpot } \\
\text { dummy }\end{array}$ & $\begin{array}{c}\text { Trading } \\
\text { activity } \\
{[-1 \rightarrow-22]} \\
\end{array}$ & Intercept & $\begin{array}{c}\bar{R}^{2} \\
\lfloor D W\rfloor\end{array}$ & $\begin{array}{c}\text { Joint } \\
p \text {-val. }\end{array}$ \\
\hline \multicolumn{6}{|l|}{ Panel A: 2002-2007 subsample } \\
\hline High individual trading fraction stocks & $\begin{array}{l}-0.075 \\
(0.024)\end{array}$ & $\begin{array}{c}0.917 \\
(0.000)\end{array}$ & $\begin{array}{c}1.251 \\
(0.003)\end{array}$ & $\begin{array}{c}69.1 \% \\
|1.1|\end{array}$ & 0.000 \\
\hline Low market cap stocks & $\begin{array}{l}-0.082 \\
(0.010)\end{array}$ & $\begin{array}{c}0.922 \\
(0.000)\end{array}$ & $\begin{array}{c}1.057 \\
(0.002)\end{array}$ & $\begin{array}{c}72.5 \% \\
\lfloor 1.0\rfloor\end{array}$ & 0.000 \\
\hline High past return stocks & $\begin{array}{l}-0.085 \\
(0.029)\end{array}$ & $\begin{array}{c}0.885 \\
(0.000)\end{array}$ & $\begin{array}{c}1.602 \\
(0.001)\end{array}$ & $\begin{array}{c}58.2 \% \\
\lfloor 1.0\rfloor\end{array}$ & 0.000 \\
\hline High past turnover stocks & $\begin{array}{l}-0.049 \\
(0.061)\end{array}$ & $\begin{array}{c}0.875 \\
(0.000) \\
\end{array}$ & $\begin{array}{c}1.706 \\
(0.001) \\
\end{array}$ & $\begin{array}{c}55.3 \% \\
\lfloor 1.2\rfloor\end{array}$ & 0.000 \\
\hline \multicolumn{6}{|l|}{ Panel B: 2003-2009 subsample } \\
\hline High individual trading fraction stocks & $\begin{array}{l}-0.053 \\
(0.104)\end{array}$ & $\begin{array}{c}0.908 \\
(0.000)\end{array}$ & $\begin{array}{c}1.068 \\
(0.001)\end{array}$ & $\begin{array}{c}68.8 \% \\
|1.0|\end{array}$ & 0.000 \\
\hline Low market cap stocks & $\begin{array}{r}-0.060 \\
(0.082)\end{array}$ & $\begin{array}{c}0.918 \\
(0.000)\end{array}$ & $\begin{array}{c}0.805 \\
(0.007)\end{array}$ & $\begin{array}{l}72.7 \% \\
\lfloor 0.9\rfloor\end{array}$ & 0.000 \\
\hline High past return stocks & $\begin{array}{l}-0.117 \\
(0.001)\end{array}$ & $\begin{array}{c}0.881 \\
(0.000)\end{array}$ & $\begin{array}{c}1.471 \\
(0.000)\end{array}$ & $\begin{array}{l}62.2 \% \\
\lfloor 0.9\rfloor\end{array}$ & 0.000 \\
\hline High past turnover stocks & $\begin{array}{l}-0.060 \\
(0.022)\end{array}$ & $\begin{array}{c}0.868 \\
(0.000)\end{array}$ & $\begin{array}{c}1.755 \\
(0.001)\end{array}$ & $\begin{array}{c}57.4 \% \\
\lfloor 1.1\rfloor\end{array}$ & 0.000 \\
\hline
\end{tabular}

Notes. Estimation results are based on the specification $\log \left(V_{p, t}\right)=\beta_{0}+\beta_{p, 1} D_{t}^{\text {Jackpot }}+$ $\beta_{p, 2} \log \left(\bar{V}_{p,[t-1 \rightarrow t-22]}\right)+$ controls $+\varepsilon_{p, t}$, for $p=H, M, L$. The regression specification is the same as Table 3. Panel A reports results for the subsample from January 22, 2002, to December 31, 2007, while Panel B restricts the sample to January 1, 2003, to December 31, 2009. The "large jackpot dummy" equals one if the jackpot size exceeds 500 million TWD. The two-sided $p$-values (reported in parenthesis) are calculated using the Newey and West (1987) heteroscedasticity and autocorrelation consistent (HAC) covariance matrix estimator. The lag length is set to 6 in Panel A and in Panel B to account for the smaller sample size of 1489 and 1741 respectively. $\bar{R}^{2}$ is adjusted $R^{2}$, and the Durbin Watson statistic is shown as $\lfloor D W\rfloor$. We report the $p$-values for the null hypothesis that all the regression coefficients are jointly equal to zero. 


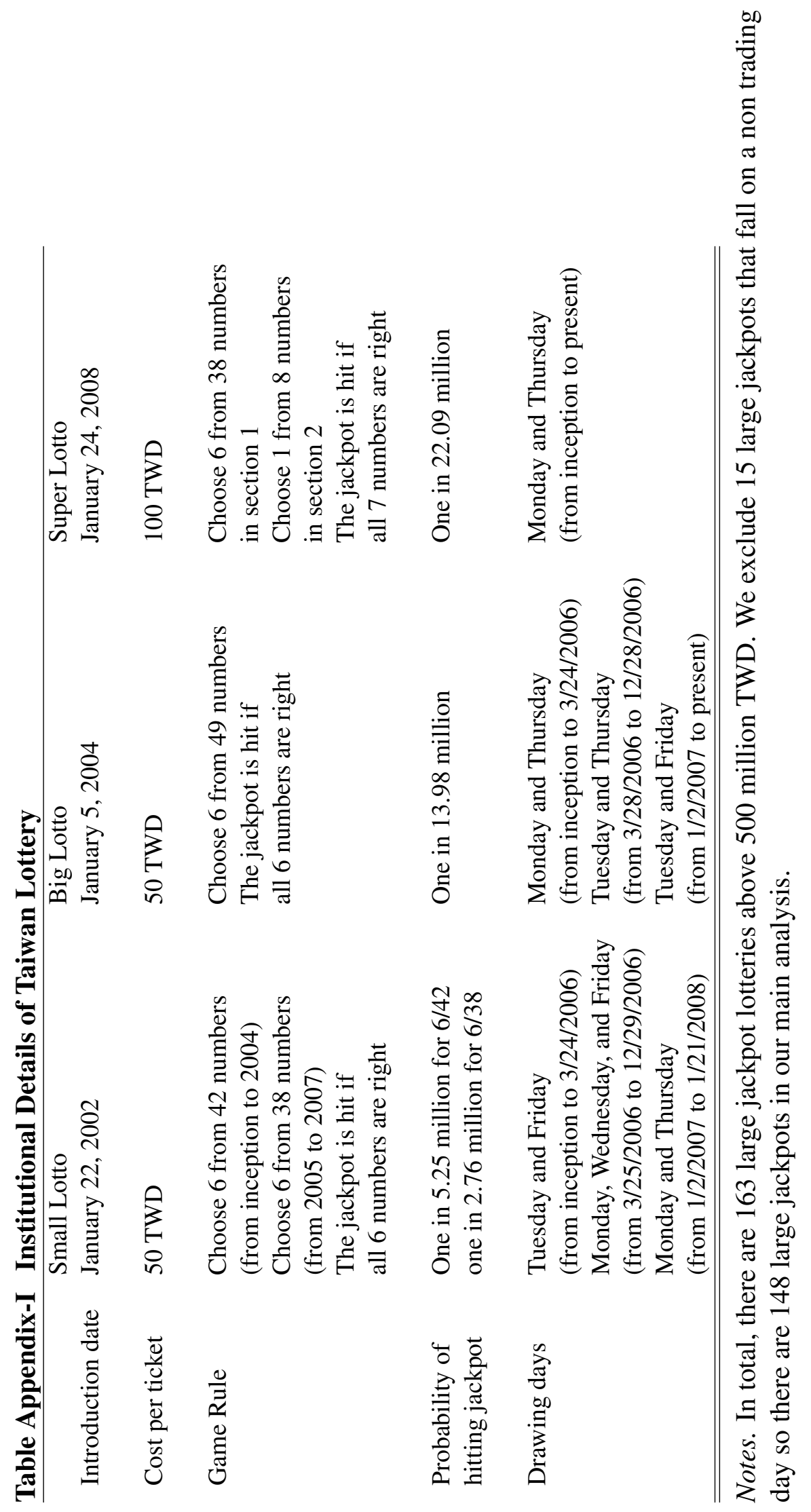



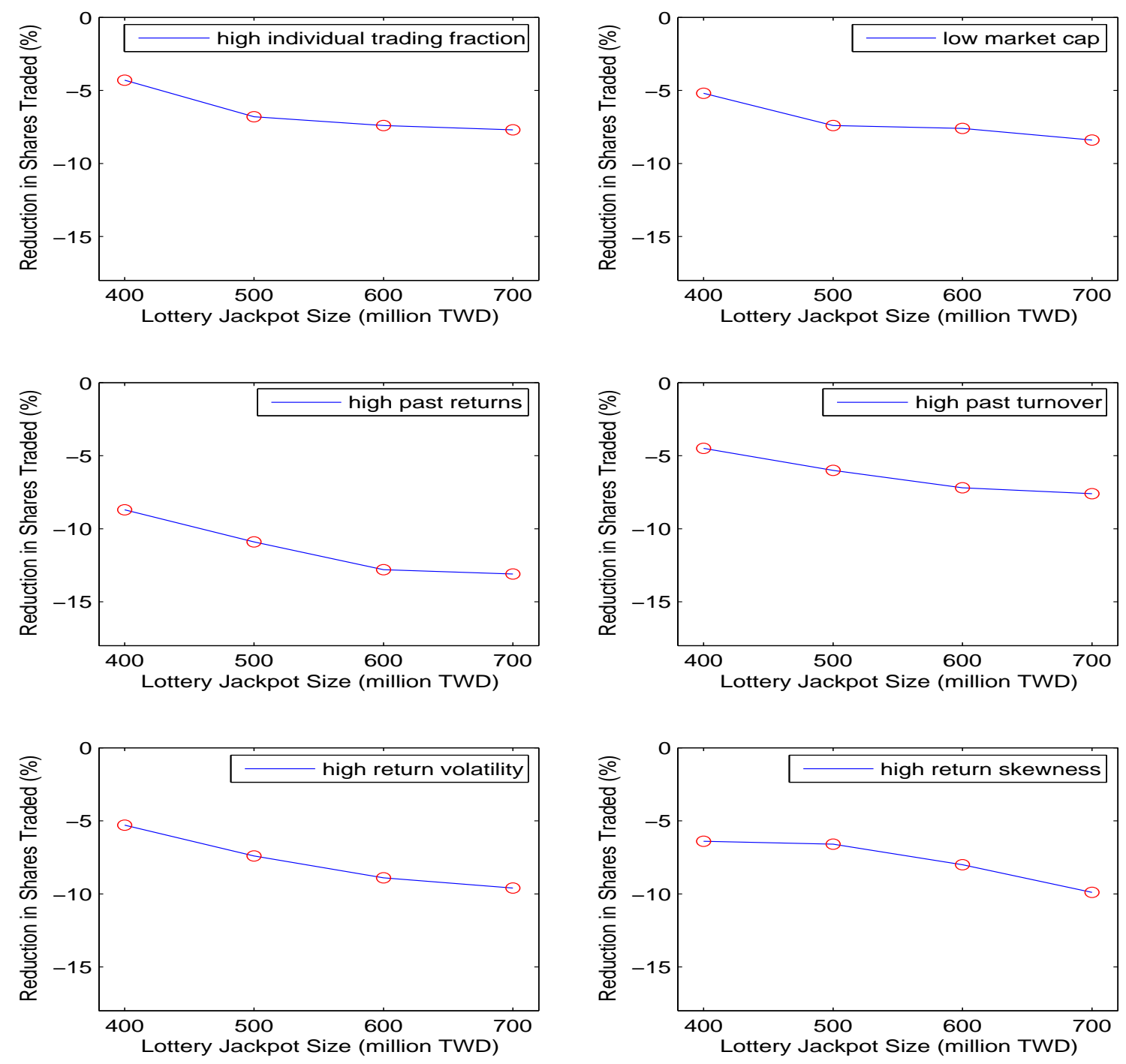

\section{Figure 1 Size of the lottery jackpot and its impact on shares traded}

Note: Plotted is the coefficient on the jackpot dummy (on the $y$-axis) versus the size of the jackpot (on the $x$-axis), shown separately for stock portfolios sharing (i) high individual trading fraction, (ii) low market capitalization, (iii) high past returns, (iv) high past turnover, (v) high return volatility, and (vi) high (positive) return skewness. The size of the jackpot is allowed to vary from 400 million TWD to 700 million TWD. The coefficients are obtained from the regressions, $\log \left(V_{p, t}\right)=\beta_{0}+$ $\beta_{p, 1} D_{t}^{\text {Jackpot }}+\beta_{p, 2} \log \left(\bar{V}_{p,[t-1 \rightarrow t-22]}\right)+$ controls $+\varepsilon_{p, t}$, where $V_{p, t}$ is the number of shares traded, and $\bar{V}_{p,[t-1 \rightarrow t-22]}$ is the average number of shares traded daily over $[t-1 \rightarrow t-22]$. The control variables include day of the week dummies, monthly unemployment rate, and quarterly GDP growth rate. 

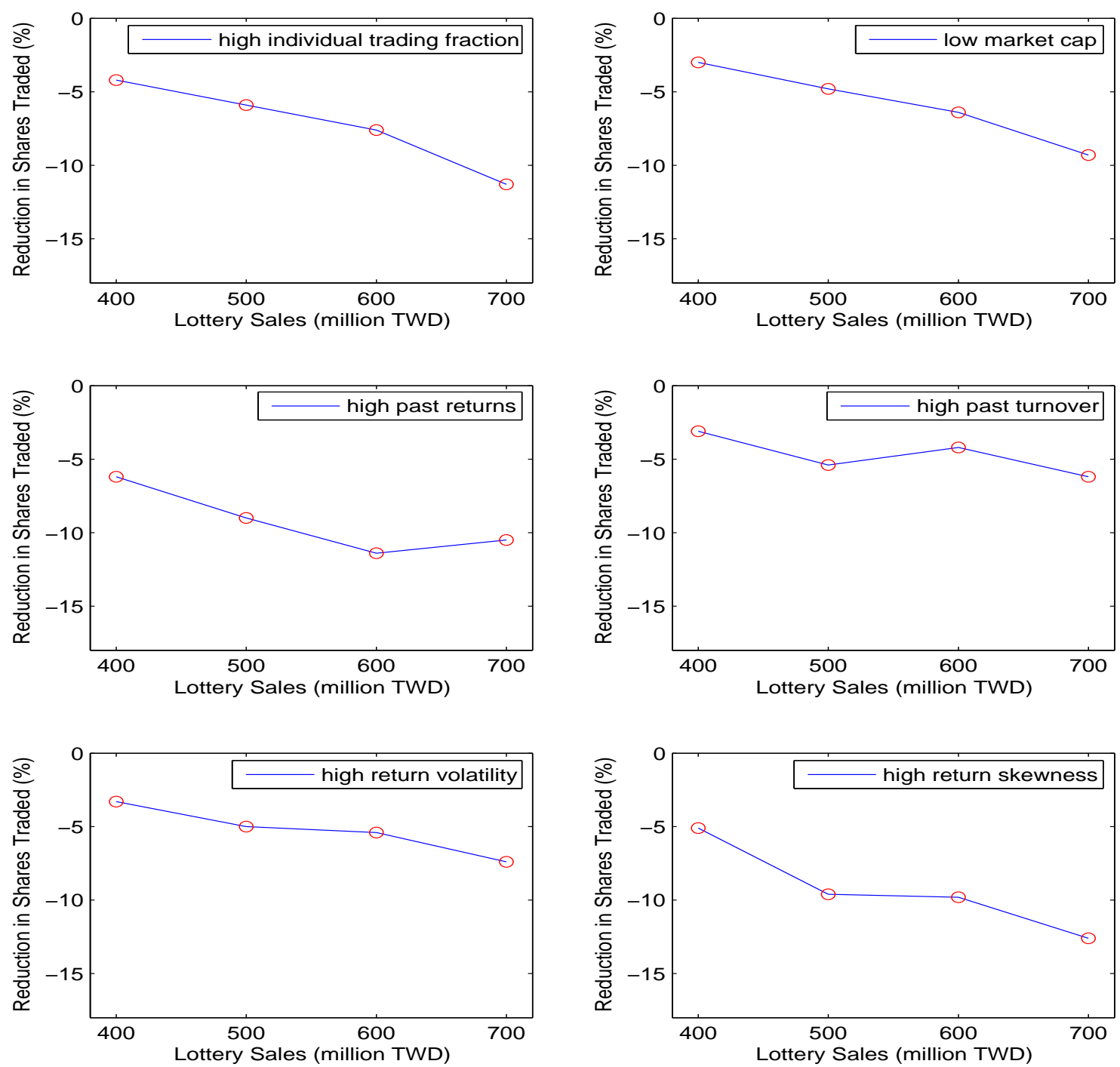

Figure 2 Size of the lottery sales and its impact on shares traded

Note: Plotted is the coefficient on the large lottery sales dummy (on the $y$-axis) versus the size of the sales (on the $x$-axis), shown separately for stock portfolios sharing (i) high individual trading fraction, (ii) low market capitalization, (iii) high past returns, (iv) high past turnover, (v) high return volatility, and (vi) high (positive) return skewness. The size of the sales is allowed to vary from 400 million TWD to 700 million TWD. The coefficients are obtained from the regressions, $\log \left(V_{p, t}\right)=\beta_{0}+\beta_{p, 1} D_{t}^{\text {Jackpot }}+\beta_{p, 2} \log \left(\bar{V}_{p,[t-1 \rightarrow t-22]}\right)+$ controls $+\varepsilon_{p, t}$, where $V_{p, t}$ is the number of shares traded, and $\bar{V}_{p,[t-1 \rightarrow t-22]}$ is the average number of shares traded daily over $[t-1 \rightarrow t-22]$. The control variables include day of the week dummies, monthly unemployment rate, and quarterly GDP growth rate. 